\title{
Orphan G protein receptor GPR55 as an emerging target in cancer therapy and management
}

This article was published in the following Dove Press journal:

Cancer Management and Research

28 June 2013

Number of times this article has been viewed

\author{
Dinorah Leyva-Illades ${ }^{1-3}$ \\ Sharon DeMorrow ${ }^{1-3}$ \\ 'Digestive Disease Research Center, \\ Scott and White Hospital, Temple, \\ TX, USA; ${ }^{2}$ Department of Internal \\ MedicineTexas A\&M Health Science \\ Center, Temple, TX, USA; ${ }^{3}$ Research \\ Service, Central Texas Veterans Health \\ Care System, Temple, TX, USA
}

\begin{abstract}
G protein-coupled receptors (GPCRs) modulate a vast array of cellular processes. The current review gives an overview of the general characteristics of GPCRs and their role in physiological conditions. In addition, it describes the current knowledge of the physiological and pathophysiological functions of GPR55, an orphan GPCR, and how it can be exploited as a therapeutic target to combat various cancers.
\end{abstract}

Keywords: GPR55, cancer, GPCR, endocannabinoids

\section{Introduction}

Signal transduction is essential for maintaining cellular homeostasis and to coordinate the activity of cells in all organisms. Proteins localized in the cell membrane serve as the interface between the outside and inside of the cell. G protein-coupled receptors (GPCRs) are the largest and most diverse group of membrane receptors in eukaryotes and are encoded by at least 800 genes in the human genome. GPCRs are also known as seven-transmembrane domain receptors, 7TM receptors, heptahelical receptors, serpentine receptors, and G protein-linked receptors. GPCRs can detect an expansive array of extracellular signals or ligands that include photons, ions, odors, pheromones, hormones, and neurotransmitters. Nonsensory GPCRs (excluding light, odor, and taste receptors) have been classified into four families: class A rhodopsin-like, class B secretin-like, class $\mathrm{C}$ metabotropic glutamate/pheromone, and frizzled receptors. They have a peculiar structure that has been highly conserved over the course of evolution and are made up of an amino acid chain, the N-terminal of which is localized outside of the cellular membrane and the C-terminal in the cytoplasm. The amino acid chain spans the cellular membrane seven times and has three intracellular and three extracellular loops.

GPCRs are called that because they exert their actions by associating with a family of heterotrimeric proteins (made up of $\alpha, \beta$, and $\gamma$ subunits) that are capable of binding and hydrolyzing guanosine triphosphate (GTP). ${ }^{1-3}$ To date, 16 different $\alpha$ subunits, five $\beta$ subunits, and $11 \gamma$ subunits have been described in mammalian tissues. When activated, these receptors undergo conformational changes that are mechanically transduced to the $\mathrm{G}$ proteins, which then initiate a cycle of activation and inactivation associated with the binding and hydrolysis of GTP. Activated G proteins can then positively or negatively modulate ion channels (mainly potassium and calcium) or the second messenger generating enzymes (ie, adenylate cyclase and phospholipase $\mathrm{C}[\mathrm{PLC}])$ that allow the signal to be propagated to the interior of the cell to ultimately affect cell function.
Department of Internal Medicine

Texas A\&M Health Science Center, I90I South Ist Street, Building 205,

Temple, TX 76504, USA

Tel + I 254743 I299

Fax + I 2547430378

Email demorrow@medicine.tamhsc.edu 
G $\alpha$ subunits have been functionally classified on the basis of the activation of adenylate cyclase. Gs activates this enzyme, whereas Gi inhibits its activity, in addition to the $\alpha$ subunits that activate PLC. Adenylate cyclase catalyzes the conversion of adenosine triphosphate to cyclic-adenosine monophosphate (cAMP), which can determine the activity of ion channel and protein kinase A. PLC catalyzes the cleavage of membrane-bound phosphatidylinositol 4,5-biphosphate into second messengers inositol 1,4,5- trisphosphate (IP3), and diacylglycerol (DAG); the latter stimulates $\mathrm{Ca}^{2+}$ release from the endoplasmic reticulum, whereas DAG can modulate protein kinase $\mathrm{C}$ activity.

Although most GPCRs can activate more than a single G $\alpha$ subtype, they show a preference for one subtype over another. GPCR function is tightly regulated, and they become desensitized after prolonged exposure to its ligand by the phosphorylation of the intracellular receptor domain, resulting in subsequent inactivation. This is generally accomplished by G protein-coupled receptor kinases, a family of mammalian serine-threonine protein kinases. This phosphorylation results in either the internalization of the GPCR or arrestin linking, which prevents $\mathrm{G}$ protein binding. ${ }^{4,5}$ It has also been shown that GPCR stimulation can lead to downstream activation of other less-common signaling effectors, including receptor tyrosine kinases, phosphoinositide 3-kinase, mitogenactivated protein kinase, extracellular signal-regulated kinase (ERK), p38 mitogen-activated protein kinase, c-Jun N-terminal kinase, Janus kinases, signal transducers, and activators of transcription. ${ }^{6-11}$ The basic components of GPCR systems and signaling are depicted in Figure 1.

\section{Physiological roles of GPCRs}

GPCRs are involved in a wide variety of physiological processes, and their dysfunction can result in several diseases. Some examples of their physiological roles include the following and are summarized in Figure 2.

\section{Vision}

The retina contains two types of photoreceptors: rods and cones. Rods are more sensitive than cones, but they are not sensitive to color. Rhodopsin is located in the disc membranes of the rod outer segments and is the visual pigment that allows humans and other vertebrate animals to see dim light by converting photons into chemical signals that stimulate biological processes in the nervous system. Rhodopsin belongs to the class A of GPCRs and was the first GPCR

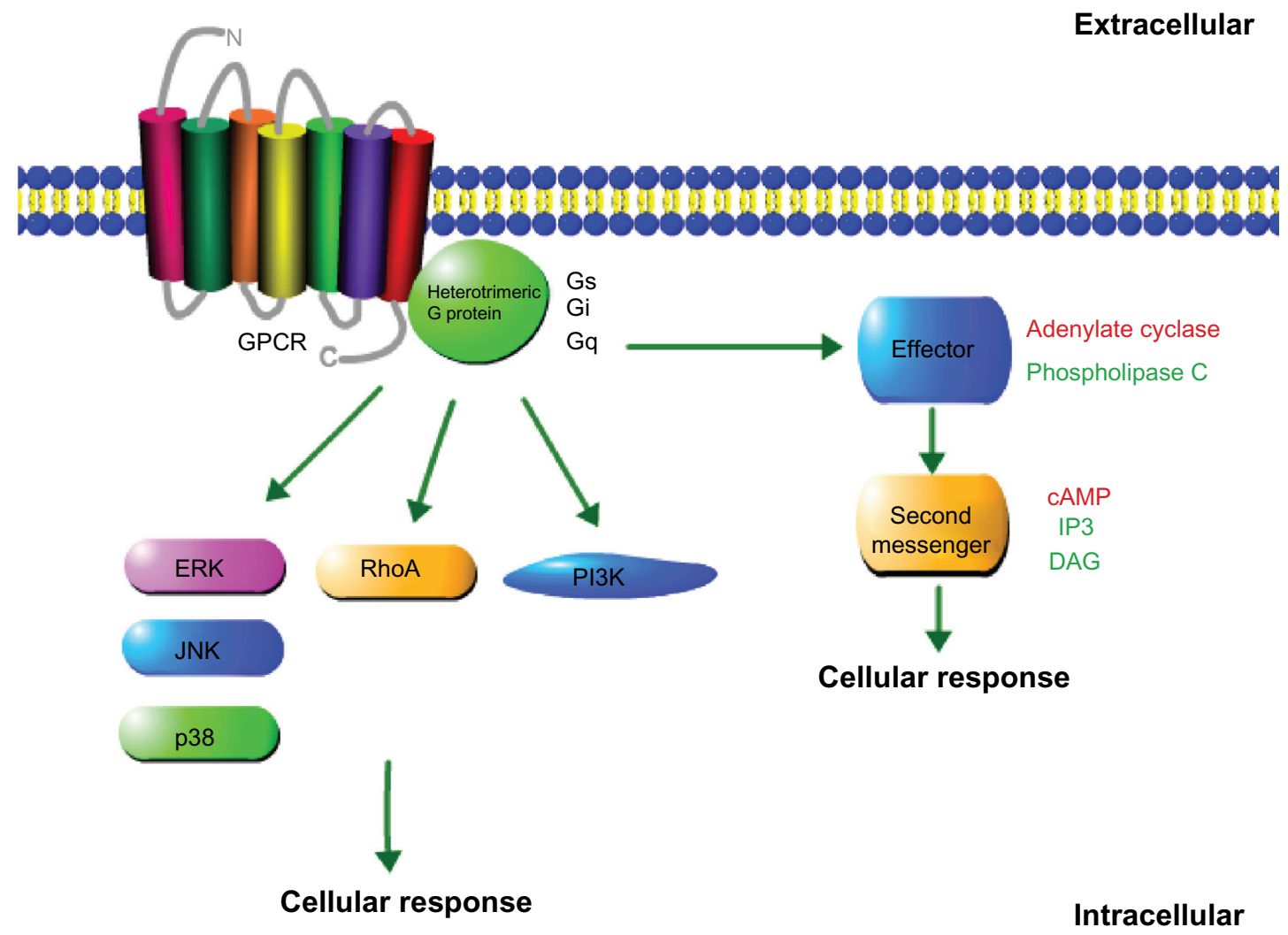

Figure I Schematic representation of the components of a GPCR system.

Abbreviations: GPCR, G protein-coupled receptor; cAMP, cyclic-adenosine monophosphate; DAG, diacylglycerol; IP3, Inositol trisphosphate; ERK, extracellular signal-regulated kinase; JNK, c-Jun N-terminal kinase; RhoA, Ras homolog gene family, member A; p38, p38 member of the mitogen-activated protein kinase family; PI3K, phosphoinosiide 3-kinase. 


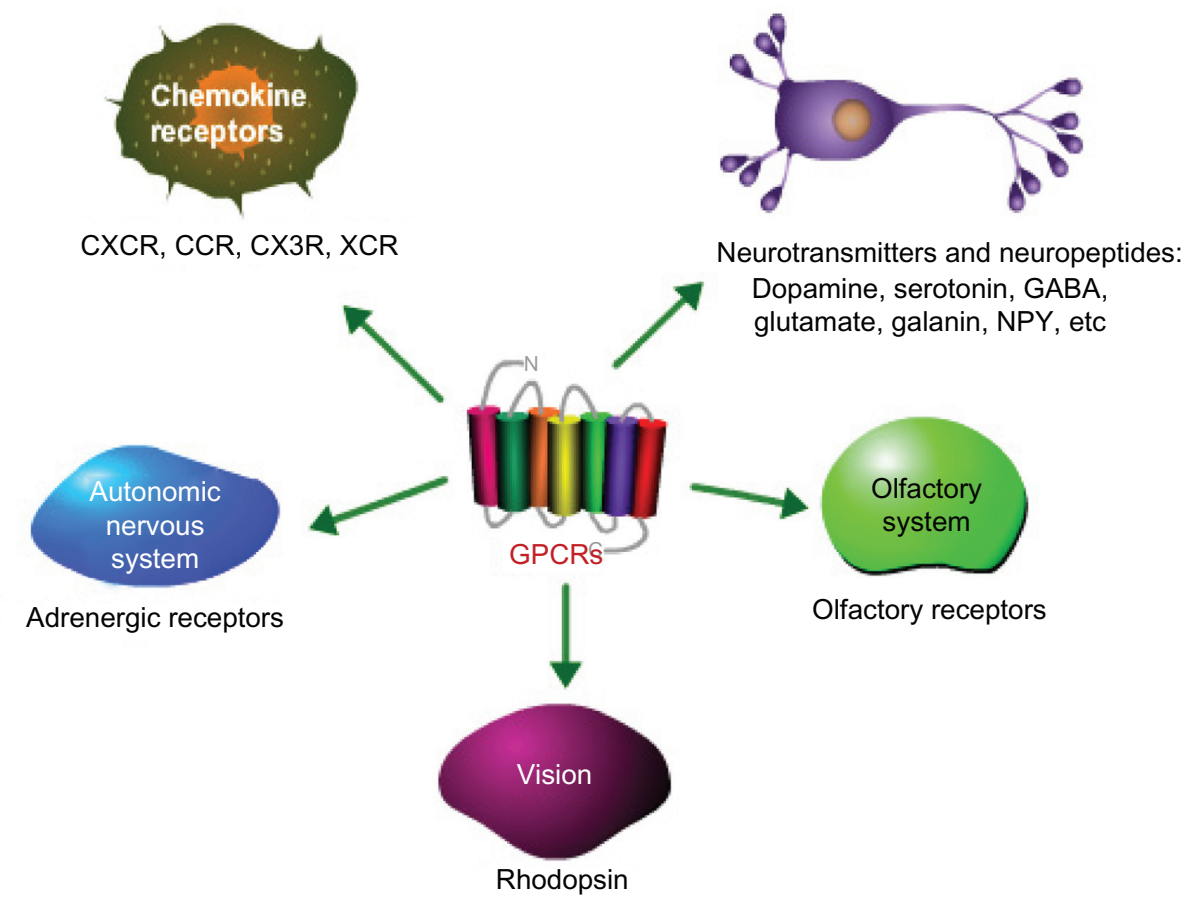

Figure 2 Examples of the physiological roles of GPCRs.

Abbreviations: GPCRs, G protein-coupled receptors; GABA, gamma-Aminobutyric acid; NPY, neuropeptide $Y$.

whose three-dimensional structure was resolved by X-ray crystallography. Light induces a conformational change in its chromophore, 11-cis-retinal, which isomerizes to the alltrans conformation leading to a change in the structure of rhodopsin, which in turn activates it. This event is followed by transducin binding to rhodopsin. Transducin is a heterotrimeric G-protein made up of the T $\alpha$ and $\mathrm{T} \beta$ and $\mathrm{T} \gamma$ subunits, and its activation triggers the signal transduction for vision. Its activation ultimately results in stimulation of cyclic guanosine monophosphate (cGMP) phosphodiesterase, opening of cGMP-gated channels, and ultimately, hyperpolarization of the membrane potential. ${ }^{12,13}$

\section{Olfactory system}

The olfactory system detects and discerns a vast array of chemical structures (odorants). To do this, it uses the odorant or olfactory receptors (ORs). ORs are expressed in olfactory sensory neurons in the olfactory epithelium, located high in the nasal cavity; each neuron only expresses a single OR. Odorant molecules dissolve in the mucus that coats the sensory neurons and bind to the ORs on these cells. This leads to the G-protein activation, adenylate cyclase activation, increase of cAMP in the cytosol, and ultimately, opening of ligand-gated sodium channels. The sodium influx depolarizes the cell and generates an action potential that is then conducted through the olfactory nerve to the brain. ${ }^{14}$

\section{Neurotransmitters}

Communication between nerve cells and muscle cells, gland cells, or other nerve cells is mediated by chemical messages transmitted by neurotransmitters or neuropeptides. The receptors for most of these molecules are GPCRs. Neurotransmitter and neuropeptide GPCRs include those for dopamine, serotonin, gamma-Aminobutyric acid (GABA), metabotropic glutamate, galanin, and neuropeptide $\mathrm{Y}$, many of which have several subtypes. ${ }^{15,16}$

\section{Chemokine receptors}

Chemokines are a family of small structurally related cytokines that have chemotactic properties and play an important role in leukocyte migration, cell survival, and effector functions. Chemokine receptors are GPCRs that are expressed in various cell types and are classified according to the subclass of chemokines they recognize (CXCR, CCR, CX3R, XCR); to date, 19 receptors have been described in mammals. A common observation is that chemokine receptors can interact with more than a single chemokine ligand. Chemokine receptors are typically coupled to G-protein of the Gi subtype. Receptor activation by chemokine ligands leads to the activation of phospholipase C and IP3 and DAG generation. IP3 then induces $\mathrm{Ca}^{2+}$ release, whereas DAG acts in conjunction with $\mathrm{Ca}^{2+}$ to activate different Protein kinase $\mathrm{C}$ isoforms. It has also been shown that chemokine 
receptor activation can lead to Ras and Rho, phosphoinositide 3-kinase, tyrosine kinases, and mitogen-activated protein kinases. ${ }^{17}$

\section{Autonomic nervous system}

Both the sympathetic and parasympathetic nervous systems are regulated by GPCR-mediated pathways. GPRCs are responsible for the control of many body functions, including blood pressure, heart rate, and digestive processes. A classic example of these is the adrenergic receptors that are expressed in many cell types and that stimulate the sympathetic nervous system. They can be broadly classified into the $\alpha$ and $\beta$ groups. $\alpha$ receptors have different subtypes: $\alpha 1$ are Gq-coupled, and $\alpha 2$ are Gi-coupled. Meanwhile, $\beta$ receptors have three subtypes $(\beta 1, \beta 2, \beta 3)$, all of which are coupled to Gs proteins. Therefore, in general, $\alpha 1$ signaling is associated with PLC and $\mathrm{Ca}^{2+}$ release, whereas $\alpha 2$ and $\beta$ are associated with adenylyl-cyclase and cAMP. ${ }^{18-20}$

\section{Orphan GPCRs}

As mentioned earlier, there are more than 800 GPCRs; however, the endogenous ligands of more than 140 of these receptors remain unidentified, and thus, their natural function is currently unknown. These receptors are termed orphan GPCRs. Deorphanization is the process of identifying ligands that are highly selective for orphan GPCRs and is a priority in orphan GPCR research. The most remarkable examples of deorphanization to date are the discoveries of novel neuropeptides, which include ghrelin, metastin, neuropeptide $\mathrm{B} / \mathrm{W}$, prokineticins $1 / 2$, neuropeptide $\mathrm{S}$, and neuromedin $\mathrm{S}$, and which have been implicated in physiological responses such as stress, sleep, and circadian rhythm..$^{21,22}$

\section{Physiological functions of GPR55}

Orphan receptor GPR55 was identified and cloned in 1999 as a novel human intron-less GPCR gene that codes for a protein of 319 amino acids and that was mapped to chromosome $2 q 37.23$ GPR55 is a member of the $\delta$ group of rhodopsin-like GPCRs and has the closest homology with a few orphan and lysophospholipid-sensitive receptors in the purinergic subfamily. ${ }^{2}$ The pharmacology of GPR55 remains controversial, as many ligands, cell types, and assays have been reported, with inconsistent results. ${ }^{24}$ However, some conclusions can be drawn: Oka et al showed that lysophosphatidylinositol (LPI) elicits several biological responses that include ERK phosphorylation and $\mathrm{Ca}^{2+}$ release via GPR55. These observations suggest that LPI is an endogenous natural ligand for GPR55 and that GPR55 is an intrinsic LPI receptor. ${ }^{25}$
Cannabinoid ligands can also activate GPR55, even though it lacks the classical cannabinoid binding pocket and so is also considered an atypical cannabinoid receptor. ${ }^{26}$ Before the identification of GPR55 as a cannabinoid receptor, the endocannabinoid system was thought to consist of the cannabinoid receptors ( $\mathrm{Cb} 1$ and $\mathrm{Cb} 2)$, their endogenous ligands (endocannabinoids), and the associated biochemical machinery (precursors, synthesis and degradation enzymes, and transporters). Anandamide (AEA) was the first endocannabinoid to be identified and acts as a partial $\mathrm{Cb} 1$ agonist and weak $\mathrm{Cb} 2$ agonist. 2-Arachidonoylglycerol (2-AG), which is also an endocannabinoid, is a $\mathrm{Cb} 1$ agonist. ${ }^{27}$

\section{Signaling}

In endothelial cells, activation of GPR55 by AEA increases ERK phosphorylation. ${ }^{28}$ Activation of GPR55 also leads to membrane rearrangements that are followed by protrusions and blebbing in HEK293 cells. ${ }^{29}$ The downstream signaling of GPR55 remains to be fully elucidated; however, it is known to use $\mathrm{G} \alpha_{13}$ for signal transduction and to activate PLC, RhoA, ROCK, ERK, p38 mitogen activated protein kinase, and $\mathrm{Ca}^{2+}$ release that can induce downstream transcription factors such as NFAT, NF- $\kappa$ B, CREB, and ATF2. ${ }^{29-33}$ It has recently been shown that GPR55 trafficking is dynamically regulated by GPCR-associated sorting protein 1 , and thus plays an important role in its availability and subsequent cellular physiology. ${ }^{34}$

\section{Central nervous system}

GPR55 messenger (m)RNA is expressed throughout the central nervous system. ${ }^{23,35-37}$ However, evidence of protein expression is currently limited. It is known that AEA can

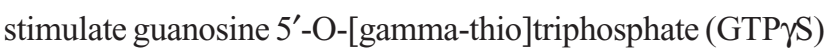
biding in brain homogenates from both wild-type and $\mathrm{Cb} 1$ knockout (KO) mice. ${ }^{38}$ Meanwhile, endocannabinoid-induced long-term depression in the hippocampus was present in $\mathrm{Cb} 1 \mathrm{KO}$ and wild-type mice. ${ }^{39}$ Additional studies have shown that microglia and astrocytes express cannabinoid targets that have yet to be identified that are capable of regulating various cellular responses. ${ }^{40}$ GPR55 is thus thought to play a role in the central nervous system; however, further studies are required to fully evaluate its significance in the central nervous system.

\section{Vasculature}

GPR55 is also thought to play a role in the vasculature. Evidence that cannabinoids can target a distinct vascular 
receptor (ie, not $\mathrm{Cb} 1$ or $\mathrm{Cb} 2$ ) came from studies of rat mesenteric arteries in which AEA-induced vasorelaxation could be blocked by Rimonabant, a Cb1 antagonist, at high concentrations. ${ }^{41}$ AEA can be released by vascular endothelial cells, and it has been shown both that in human umbilical vein endothelial cells, anandamiee increases $\mathrm{Ca}^{2+}$ release, and that this is dependent on integrin clustering. ${ }^{28}$ Endothelial cells may also regulate GPR55-mediated physiology through the autocrine release of LPI after intracellular Phospholipase A2 $\left(\right.$ PLA $\left._{2}\right)$-mediated lipid breakdown. ${ }^{42}$ When GPR55 is downregulated in primary human dermal microvascular endothelial cells, there is decreased angiogenesis, which suggests endogenous GPR55 agonists are present. ${ }^{43}$

\section{Inflammation}

Experiments performed in GPR55-deficient mice have shown that it also plays a role in neuropathic pain. These KO mice were highly resistant to mechanical hyperalgesia associated with Freund's complete adjuvant-induced inflammation or partial nerve ligation. Cytokine profiling of $\mathrm{KO}$ mice showed differences compared with wild-type mice, which may explain the lack of inflammatory mechanical hyperalgesia in the $\mathrm{KO}$ models. ${ }^{36}$ GPR55 expression has also been found in cells of the immune system. Recent studies suggest that GPR55 regulates $\mathrm{Cb} 2$ function in human neutrophils. Coactivation of GPR55 by LPI and Cb2 by 2-AG led to increased neutrophil migration and polarization morphology, whereas 2-AG alone only showed neutrophil elongation. ${ }^{44,45}$ A role for GPR55 in intestinal inflammation has also been studied. GPR55 KO mice have decreased inflammation in a model of dextran sulfate sodium-induced colitis compared with their wild-type counterparts. ${ }^{46}$ In a murine model of acute pancreatitis (AP), administration of O-1602, an agonist of GPR55, improved the pathological changes of mice with AP and decreased interleukin 6 and tumor necrosis alpha levels, suggesting that O-1602 has anti-inflammatory effects. ${ }^{47}$

\section{Bone}

GPR55 expression has been shown in human and mouse osteoblasts and osteoclasts. Interestingly, GPR55 expression was higher in human osteoclasts than in macrophage progenitors. O-1602 and LPI inhibited mouse osteoclast formation and stimulated polarization and reabsorption through Rho and ERK. These effects were not observed in macrophages isolated from GPR55 KO mice. GPR55 KO mice also had increased bone mass, but bone formation was unaffected. ${ }^{48}$ These observations suggest that GPR55 may play a role in bone physiology by regulating osteoclast number and function.

\section{Pancreas}

High GPR55 mRNA expression was found in pancreatic islets, and protein expression was found in insulinsecreting $\beta$-cells. Activation of GPR55 with O-1602, an agonist, resulted in the increase of $\mathrm{Ca}^{2+}$ release and insulin secretion stimulated by glucose. The latter was reduced in GPR55 KO mice. Further in vivo experiments showed that GPR55 activation increases glucose tolerance and plasma insulin levels. ${ }^{49}$ These data suggest that GPR55 expression in the pancreas may play a role in glucose homeostasis.

\section{Gastrointestinal system}

GPR55 mRNA expression has been found in the duodenum, jejunum, ileum, and colon of rodents..$^{35,46,50}$ It also is found in mucosal scrapings and longitudinal-myenteric plexus preparations of colon, which suggests that it is present in both gastrointestinal epithelial cells and enteric neurons. ${ }^{50}$ To this effect, GPR55 has been detected by immunohistochemistry in rat ileum enteric neurons. This study also showed that GPR55 expression was higher in rats treated with lipopolysaccharide, indicating both a potential role in the gut response to inflammation and that $\mathrm{O}-1602$ can reduce spontaneous contractions in the rat ileum, but not in the colon or jejunum. ${ }^{46}$ Together, these data suggest that GPR55 may play a role in gastrointestinal physiology, including motility and secretion.

A summary of the physiological functions of GPR55 is shown in Figure 3.

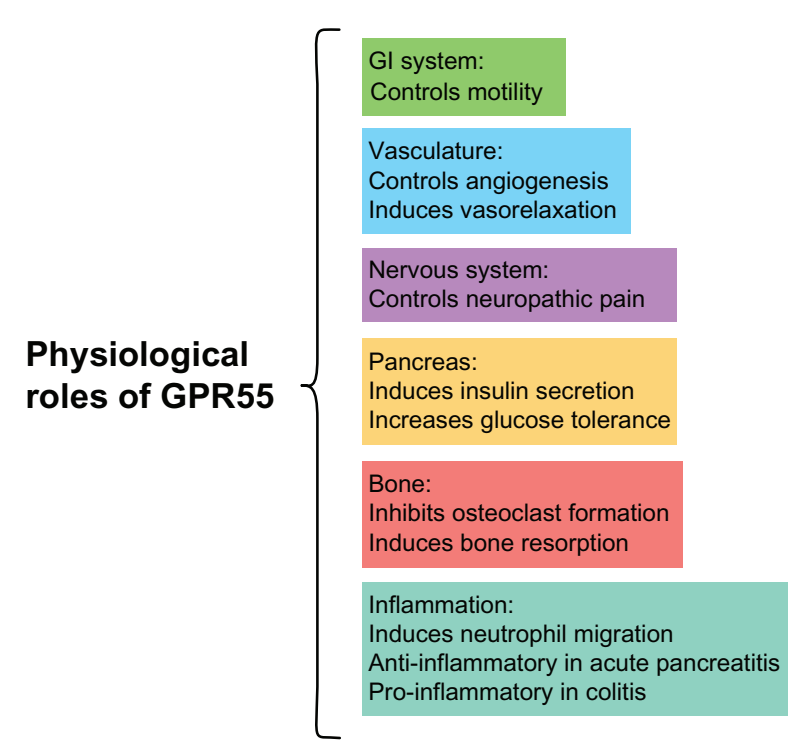

Figure 3 Summary of GPR55 physiological roles.

Abbreviations: GI, gastrointestinal; GPR55, G protein-coupled receptor 55 . 


\section{Role of GPR55 in human cancer}

Many GPCRs have been associated with tumorigenesis and metastasis. Neoplastic cells frequently hijack their normal physiological function to survive, proliferate, evade the immune system, induce angiogenesis, and promote invasion and metastasis, and the aberrant expression or mutation of many GPCRs have been linked to various cancers. ${ }^{51}$ As mentioned before, LPI is a GPR55 endogenous ligand and is now known to be secreted by fibroblasts and epithelial cancer cells and transformed thyroid cells, leading to mitogenic effects. ${ }^{52,53}$ In fact, patients with ovarian cancer have increased LPI plasma levels compared with healthy control patients. ${ }^{54}$ Given that LPI is a potent inducer of GPR55, many studies have assessed the role of GPR55 in cancer. A summary of the roles and known signaling of GPR55 in different cancers is shown in Figure 4.

\section{Cholangiocarcinoma}

Cholangiocarcinomas arise from the neoplastic transformation of cholangiocytes, the epithelial cells that line the biliary ducts. Symptoms are usually only evident after blockage of the bile duct and, at this late stage, chemotherapy and radiotherapy are relatively ineffectual, leaving surgical resection as the only option for treatment. Because of this, these biliary cancers have a poor prognosis, and improved treatments are urgently needed.

We have previously shown that AEA exerts growthsuppressing effects on cholangiocarcinoma by inducing apoptosis. ${ }^{55}$ This effect could not be blocked by $\mathrm{Cb} 1$, $\mathrm{Cb} 2$, or VR1 antagonists or by the specific $\mathrm{G}_{\mathrm{i} / \mathrm{o}}$ inhibitor, pertussis toxin. ${ }^{55}$ In addition, we have previously shown that AEA-induced cell death is dependent on the stabilization of lipid rafts and the subsequent recruitment of the death receptor, Fas, into these structures. ${ }^{55}$ With the identification of GPR55 as a novel cannabinoid receptor capable of regulating the effects of AEA, ${ }^{26}$ we reassessed the mechanism by which AEA exerts its effects and have shown that both malignant and nonmalignant cholangiocytes express GPR55 to a similar degree, a specific GPR55 agonist has a suppressive effect on cholangiocarcinoma growth both in vitro and in vivo similar to that of AEA, knocking down the expression of GPR55 prevents the antiproliferative action of AEA, and the growthsuppressing effects of GPR55 activation by AEA require Go12 and Jun N-terminal kinase activation and subsequent translocation of Fas into the lipid raft structures. These data suggest that GPR55 offers an intriguing target for the design of potential chemotherapeutic agents.

In addition to the lipid-raft-mediated effects of AEA, we have shown that AEA induces a concomitant activation of the noncanonical WnT signaling pathway via upregulation of Wnt $5,{ }^{56}$ as well as an increase in the proteolytic processing, and hence activation of the Notch 1 signaling pathway. ${ }^{57}$ How these seemingly independent observations fit together is a topic of ongoing research in our laboratory. The dependence and recruitment of the $\gamma$-secretase complex to lipid raft structures has previously been shown to modulate $\gamma$-secretase activity; ${ }^{58}$ therefore, it is conceivable that agents that stabilize or disrupt lipid raft structures such as cannabinoids ${ }^{55}$ may indeed also regulate the Notch signaling pathway. Furthermore, activation of the Wnt signaling pathway has been shown to overlap and

\section{GPR55 in cancer}

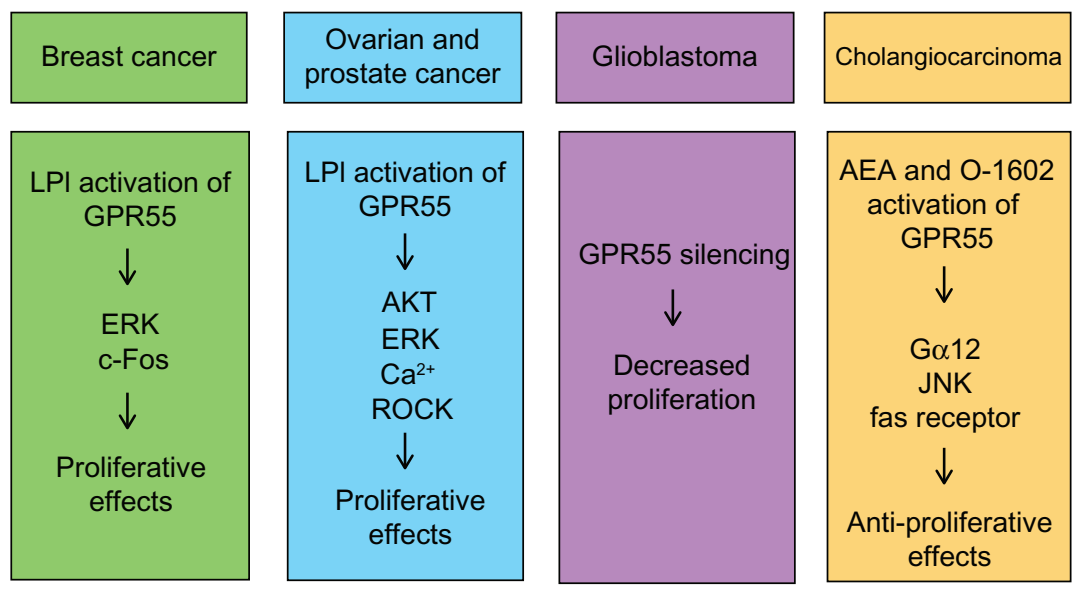

Figure 4 Summary of current known roles of GPR55 in cancer.

Abbreviations: AEA, anandamide; AKT, Protein Kinase B; ERK, extracellular signal-regulated kinase; GPR55, G protein-coupled receptor 55; JNK, c-Jun N-terminal kinase; LPI, lysophosphatidylinositol; ROCK, RhoA-associated protein kinase. 
cross-talk with the Notch signaling pathway. ${ }^{59-61}$ Indeed, activation of Notch 1 has been shown to upregulate the expression of Wnt5a in a number of cell models. ${ }^{60}$ The involvement of lipid rafts in the differential activation of the Notch signaling pathways by endocannabinoids and how the Wnt and Notch signaling pathways interact in these conditions are a topic of ongoing research in our laboratory.

\section{Breast cancer}

GPR55 expression has been detected in the highly metastatic MDA-MB-231 human breast cancer cell line and, interestingly, was much more abundantly expressed in this cell line compared with in the less-metastatic human cell line, MCF-7. LPI treatment of MDA-MB-231 cells significantly enhanced cell chemotaxis, which was prevented by transfection with GPR55 small interfering (si)RNA. ${ }^{62}$ Andradas et $\mathrm{al}^{63}$ have shown GPR55 expression in human breast tumors and found that higher levels of this receptor were evident in tumors with worse prognosis. They also observed an association between increased GPR55 levels and high proliferative indexes, but not tumor size or metastasis. Downregulation of GPR55 in EVSA-T breast cancer cells decreased cell viability and ERK phosphorylation; in an opposite manner, GPR55 overexpression increased cell viability and ERK phosphorylation. The proliferative effects mediated by GPR55 are thought to be a result of ERK activation and downstream expression of c-Fos.

\section{Prostate and ovarian cancer}

GPR55 mRNA and protein expression has been observed in human ovarian (OVCAR3 and A2780) and prostate (PC-3 and DU145) cancer cell lines. LPI treatment of these cells induced a transient increase in intracellular $\mathrm{Ca}^{2+}$ and ERK and Protein Kinase B (Akt) phosphorylation. Downregulation of GPR55 expression using specific siRNA reversed these effects, suggesting that LPI effects in ovarian and prostate cancer cells are mediated by GPR55. Using a pharmacological inhibitor of ROCK, it was determined that ROCK signaling is involved downstream of GPR55 and upstream of ERK and that it does not play a role in $\mathrm{Ca}^{2+}$ release. GPR55 downregulation also inhibited cell proliferation independent of exogenous LPI, suggesting that these cancer cells release LPI and promote their proliferation in an autocrine loop via GPR55. ${ }^{64}$

\section{Glioblastoma}

Higher histological grades of human glioblastomas have been reported in association with increased GPR55 expression. In a xenograft model of glioblastoma in which GPR55 was silenced, it reduced the number of proliferation cells within the tumors and slowed tumor growth. ${ }^{63}$

\section{Other cancers}

A link between high GPR55 levels and increasingly advanced stages of human pancreatic ductal adenocarcinoma has been observed. ${ }^{63}$ Similarly, recent studies have shown that GPR55 is upregulated in human skin tumors and other squamous cell carcinomas. ${ }^{65}$ GPR55 expression has also been reported in lymphoblastoid cell lines, human astrocytoma, melanoma, and B lymphoblastoma. ${ }^{32,63}$

\section{Critical analysis of the potential for targeting GPR55 in human cancer}

GPR55 physiology is still highly debatable, as evidenced by the controversial pharmacology and signaling reported to date. However, given its widespread distribution and increasingly clear evidence that it may play an important role in tumor progression, it should be considered a novel cancer biomarker and/or therapeutic target. Indeed, in patients with ovarian cancer, its endogenous ligand is increased, and in many other cancers, increased levels of GPR55 expression correlate with increased tumor growth and worse outcome. In contrast, GPR55 plays an antiproliferative role in cholangiocarcinoma. GPR55 antagonists may prove beneficial in slowing tumor proliferation and angiogenesis in these particular cancer types; however, further analysis of its role in other types of cancer and in in vivo models will be necessary.

\section{Conclusion}

Because of its cannabinoid sensitivity and similar tissue localization, GPR55 can explain some of the effects observed that are not mediated by the canonical cannabinoid receptors $\mathrm{Cb} 1$ and $\mathrm{Cb} 2$. To date, LPI has been described as the endogenous GPR55 ligand, but endocannabinoids AEA, 2-AG, and the agonist O-1602 can also activate it. Therefore, GPR55 is likely the first LPI receptor described. Lysophospholid signaling systems such as LPA and sphingosine-1-phosphate have been associated with many physiological and pathophysiological states, including cell differentiation, smooth muscle contraction, cancer, multiple sclerosis, cardiovascular disease, and asthma ${ }^{66,67}$ Further understanding of the interplay between LPI and GPR55 and its effect on cellular and organ physiology will likely reveal its role in pathophysiological processes. Additional studies to elucidate the role of endocannabinoid GPR55 ligands in GPR55 physiology and pathophysiology are also warranted, as endocannabinoids have been shown to play a role in inflammation, ${ }^{68}$ cancer, ${ }^{69}$ liver disease, ${ }^{70}$ 
and inflammatory disorders of the intestinal tract, ${ }^{71}$ to name a few. In conclusion, GPR55 has emerged as a promising candidate for the development of novel anticancer therapeutic strategies.

\section{Acknowledgments}

Portions of these studies were supported by grants awarded to Dr DeMorrow: American Cancer Society Research Scholar Award (RSC118760), National Institutes of Health K01 Award (DK078532), and National Institutes of Health R03 Award (DK088012). This material is the result of work supported with resources and the use of facilities at the Central Texas Veterans Health Care System in Temple, TX, USA.

\section{Disclosure}

The authors report no conflicts of interest in this work.

\section{References}

1. Venkatakrishnan AJ, Deupi X, Lebon G, Tate CG, Schertler GF, Babu MM. Molecular signatures of G-protein-coupled receptors. Nature. 2013;494(7436):185-194.

2. Fredriksson R, Lagerström MC, Lundin LG, Schiöth HB. The G-protein-coupled receptors in the human genome form five main families. Phylogenetic analysis, paralogon groups, and fingerprints. Mol Pharmacol. 2003;63(6):1256-1272.

3. Liapakis G, Cordomí A, Pardo L. The G-protein coupled receptor family: actors with many faces. Curr Pharm Des. 2012;18(2):175-185.

4. Gurevich EV, Tesmer JJ, Mushegian A, Gurevich VV. G protein-coupled receptor kinases: more than just kinases and not only for GPCRs. Pharmacol Ther. 2012;133(1):40-69.

5. Cabrera-Vera TM, Vanhauwe J, Thomas TO, et al. Insights into G protein structure, function, and regulation. Endocr Rev. 2003;24(6):765-781.

6. Pelletier S, Duhamel F, Coulombe P, Popoff MR, Meloche S. Rho family GTPases are required for activation of Jak/STAT signaling by G protein-coupled receptors. Mol Cell Biol. 2003;23(4):1316-1333.

7. Schulte G, Fredholm BB. Signalling from adenosine receptors to mitogen-activated protein kinases. Cell Signal. 2003;15(9):813-827.

8. Waters C, Pyne S, Pyne NJ. The role of G-protein coupled receptors and associated proteins in receptor tyrosine kinase signal transduction. Semin Cell Dev Biol. 2004;15(3):309-323.

9. Rozengurt E. Mitogenic signaling pathways induced by $\mathrm{G}$ proteincoupled receptors. J Cell Physiol. 2007;213(3):589-602.

10. Koizumi A, Tanaka KF, Yamanaka A. The manipulation of neural and cellular activities by ectopic expression of melanopsin. Neurosci Res. 2013;75(1):3-5.

11. Osmond RI, Crouch MF, Dupriez VJ. An emerging role for kinase screening in GPCR drug discovery. Curr Opin Mol Ther. 2010;12(3): 305-315.

12. Zhou XE, Melcher K, Xu HE. Structure and activation of rhodopsin. Acta Pharmacol Sin. 2012;33(3):291-299.

13. Sung CH, Chuang JZ. The cell biology of vision. J Cell Biol. 2010;190(6): 953-963.

14. DeMaria S, Ngai J. The cell biology of smell. J Cell Biol. 2010;191(3): 443-452.

15. Hoyer D, Bartfai T. Neuropeptides and neuropeptide receptors: drug targets, and peptide and non-peptide ligands: a tribute to Prof Dieter Seebach. Chem Biodivers. 2012;9(11):2367-2387.

16. Betke KM, Wells CA, Hamm HE. GPCR mediated regulation of synaptic transmission. Prog Neurobiol. 2012;96(3):304-321.
17. Mortier A, Van Damme J, Proost P. Overview of the mechanisms regulating chemokine activity and availability. Immunol Lett. 2012;145(1-2):2-9.

18. Wallukat G. The beta-adrenergic receptors. Herz. 2002;27(7): 683-690.

19. Piascik MT, Perez DM. Alpha1-adrenergic receptors: new insights and directions. J Pharmacol Exp Ther. 2001;298(2):403-410.

20. Kanagy NL. Alpha(2)-adrenergic receptor signalling in hypertension. Clin Sci (Lond). 2005;109(5):431-437.

21. Tang XL, Wang Y, Li DL, Luo J, Liu MY. Orphan G protein-coupled receptors (GPCRs): biological functions and potential drug targets. Acta Pharmacol Sin. 2012;33(3):363-371.

22. Chung S, Funakoshi T, Civelli O. Orphan GPCR research. Br J Pharmacol. 2008;153 Suppl 1:S339-S346.

23. Sawzdargo M, Nguyen T, Lee DK, et al. Identification and cloning of three novel human G protein-coupled receptor genes GPR52, PsiGPR53 and GPR55: GPR55 is extensively expressed in human brain. Brain Res Mol Brain Res. 1999;64(2):193-198.

24. Ross RA. The enigmatic pharmacology of GPR55. Trends Pharmacol Sci. 2009;30(3):156-163.

25. Oka S, Nakajima K, Yamashita A, Kishimoto S, Sugiura T. Identification of GPR55 as a lysophosphatidylinositol receptor. Biochem Biophys Res Commun. 2007;362(4):928-934.

26. Petitet F, Donlan M, Michel A. GPR55 as a new cannabinoid receptor: still a long way to prove it. Chem Biol Drug Des. 2006;67(3):252-253.

27. Fonseca BM, Costa MA, Almada M, Correia-da-Silva G, Teixeira NA. Endogenous cannabinoids revisited: A biochemistry perspective. Prostaglandins Other Lipid Mediat. 2013;102-103:13-30.

28. Waldeck-Weiermair M, Zoratti C, Osibow K, et al. Integrin clustering enables anandamide-induced $\mathrm{Ca} 2+$ signaling in endothelial cells via GPR55 by protection against CB1-receptor-triggered repression. J Cell Sci. 2008;121(Pt 10):1704-1717.

29. Kapur A, Zhao P, Sharir H, et al. Atypical responsiveness of the orphan receptor GPR55 to cannabinoid ligands. J Biol Chem. 2009;284(43): 29817-29827.

30. Henstridge CM, Balenga NA, Ford LA, Ross RA, Waldhoer M, Irving AJ. The GPR55 ligand L-alpha-lysophosphatidylinositol promotes RhoA-dependent $\mathrm{Ca} 2+$ signaling and NFAT activation. FASEB J. 2009;23(1):183-193.

31. Lauckner JE, Jensen JB, Chen HY, Lu HC, Hille B, Mackie K. GPR55 is a cannabinoid receptor that increases intracellular calcium and inhibits M current. Proc Natl Acad Sci U S A. 2008;105(7):2699-2704.

32. Oka S, Kimura S, Toshida T, Ota R, Yamashita A, Sugiura T. Lysophosphatidylinositol induces rapid phosphorylation of p38 mitogen-activated protein kinase and activating transcription factor 2 in HEK293 cells expressing GPR55 and IM-9 lymphoblastoid cells. J Biochem. 2010;147(5):671-678.

33. Henstridge CM, Balenga NA, Schröder R, et al. GPR55 ligands promote receptor coupling to multiple signalling pathways. Br J Pharmacol. 2010;160(3):604-614.

34. Karg1 J, Balenga NA, Platzer W, Martini L, Whistler JL, Waldhoer M. The GPCR-associated sorting protein 1 regulates ligand-induced downregulation of GPR55. Br J Pharmacol. 2012;165(8):2611-2619.

35. Ryberg E, Larsson N, Sjögren S, et al. The orphan receptor GPR55 is a novel cannabinoid receptor. Br J Pharmacol. 2007;152(7):1092-1101.

36. Staton PC, Hatcher JP, Walker DJ, et al. The putative cannabinoid receptor GPR55 plays a role in mechanical hyperalgesia associated with inflammatory and neuropathic pain. Pain. 2008;139(1): 225-236.

37. Pietr M, Kozela E, Levy R, et al. Differential changes in GPR55 during microglial cell activation. FEBS Lett. 2009;583(12):2071-2076.

38. Breivogel CS, Griffin G, Di Marzo V, Martin BR. Evidence for a new $\mathrm{G}$ protein-coupled cannabinoid receptor in mouse brain. Mol Pharmacol. 2001;60(1):155-163.

39. Rouach N, Nicoll RA. Endocannabinoids contribute to short-term but not long-term mGluR-induced depression in the hippocampus. Eur $J$ Neurosci. 2003;18(4):1017-1020. 
40. Stella N. Cannabinoid and cannabinoid-like receptors in microglia, astrocytes, and astrocytomas. Glia. 2010;58(9):1017-1030.

41. White R, Hiley CR. The actions of some cannabinoid receptor ligands in the rat isolated mesenteric artery. Br J Pharmacol. 1998;125(3): 533-541.

42. Kaya H, Patton GM, Hong SL. Bradykinin-induced activation of phospholipase $\mathrm{A} 2$ is independent of the activation of polyphosphoinositidehydrolyzing phospholipase C. J Biol Chem. 1989;264(9):4972-4977.

43. Zhang X, Maor Y, Wang JF, Kunos G, Groopman JE. Endocannabinoidlike $\mathrm{N}$-arachidonoyl serine is a novel pro-angiogenic mediator. $\mathrm{Br} \mathrm{J}$ Pharmacol. 2010;160(7):1583-1594.

44. Balenga NA, Aflaki E, Kargl J, et al. GPR55 regulates cannabinoid 2 receptor-mediated responses in human neutrophils. Cell Res. 2011; 21(10):1452-1469.

45. Kurihara R, Tohyama Y, Matsusaka S, et al. Effects of peripheral cannabinoid receptor ligands on motility and polarization in neutrophillike HL60 cells and human neutrophils. J Biol Chem. 2006;281(18): 12908-12918.

46. Schicho R, Bashashati M, Bawa M, et al. The atypical cannabinoid O-1602 protects against experimental colitis and inhibits neutrophil recruitment. Inflamm Bowel Dis. 2011;17(8):1651-1664.

47. Li K, Feng JY, Li YY, et al. Anti-inflammatory role of cannabidiol and O-1602 in cerulein-induced acute pancreatitis in mice. Pancreas. 2013;42(1):123-129.

48. Whyte LS, Ryberg E, Sims NA, et al. The putative cannabinoid receptor GPR55 affects osteoclast function in vitro and bone mass in vivo. Proc Natl Acad Sci U SA. 2009;106(38):16511-16516.

49. Romero-Zerbo SY, Rafacho A, Díaz-Arteaga A, et al. A role for the putative cannabinoid receptor GPR55 in the islets of Langerhans. $J$ Endocrinol. 2011;211(2):177-185.

50. Lin XH, Yuece B, Li YY, et al. A novel CB receptor GPR55 and its ligands are involved in regulation of gut movement in rodents. Neurogastroenterol Motil. 2011;23(9):862-e342.

51. Dorsam RT, Gutkind JS. G-protein-coupled receptors and cancer. Nat Rev Cancer. 2007;7(2):79-94.

52. Falasca M, Iurisci C, Carvelli A, Sacchetti A, Corda D. Release of the mitogen lysophosphatidylinositol from $\mathrm{H}$-Ras-transformed fibroblasts; a possible mechanism of autocrine control of cell proliferation. Oncogene. 1998;16(18):2357-2365.

53. Falasca M, Corda D. Elevated levels and mitogenic activity of lysophosphatidylinositol in k-ras-transformed epithelial cells. Eur J Biochem. 1994;221(1):383-389.

54. Xiao Y, Chen Y, Kennedy AW, Belinson J, Xu Y. Evaluation of plasma lysophospholipids for diagnostic significance using electrospray ionization mass spectrometry (ESI-MS) analyses. Ann N Y Acad Sci. 2000;905:242-259.

55. DeMorrow S, Glaser S, Francis H, et al. Opposing actions of endocannabinoids on cholangiocarcinoma growth: recruitment of Fas and Fas ligand to lipid rafts. J Biol Chem. 2007;282(17):13098-13113.

56. DeMorrow S, Francis H, Gaudio E, et al. The endocannabinoid anandamide inhibits cholangiocarcinoma growth via activation of the noncanonical Wnt signaling pathway. Am J Physiol Gastrointest Liver Physiol. 2008;295(6):G1150-G1158.
57. Frampton G, Coufal M, Li H, Ramirez J, DeMorrow S. Opposing actions of endocannabinoids on cholangiocarcinoma growth is via the differential activation of Notch signaling. Exp Cell Res. 2010;316(9): $1465-1478$.

58. Gamerdinger M, Clement AB, Behl C. Effects of sulindac sulfide on the membrane architecture and the activity of gamma-secretase. Neuropharmacology. 2008;54(6):998-1005.

59. Collu GM, Brennan K. Cooperation between Wnt and Notch signalling in human breast cancer. Breast Cancer Res. 2009;(3):105.

60. Katoh M, Katoh M. Transcriptional mechanisms of WNT5A based on NF-kappaB, Hedgehog, TGFbeta, and Notch signaling cascades. Int $J$ Mol Med. 2009;23(6):763-769.

61. Nakamura T, Tsuchiya K, Watanabe M. Crosstalk between Wnt and Notch signaling in intestinal epithelial cell fate decision. J Gastroenterol. 2007;42(9):705-710.

62. Ford LA, Roelofs AJ, Anavi-Goffer S, et al. A role for L-alpha-lysoph osphatidylinositol and GPR55 in the modulation of migration, orientation and polarization of human breast cancer cells. Br J Pharmacol. 2010;160(3):762-771.

63. Andradas C, Caffarel MM, Pérez-Gómez E, et al. The orphan G proteincoupled receptor GPR55 promotes cancer cell proliferation via ERK. Oncogene. 2011;30(2):245-252.

64. Piñeiro R, Maffucci T, Falasca M. The putative cannabinoid receptor GPR55 defines a novel autocrine loop in cancer cell proliferation. Oncogene. 2011;30(2):142-152.

65. Pérez-Gómez E, Andradas C, Flores JM, et al. The orphan receptor GPR55 drives skin carcinogenesis and is upregulated in human squamous cell carcinomas. Oncogene. 2013;32(20):2534-2542.

66. Takabe K, Paugh SW, Milstien S, Spiegel S. "Inside-out" signaling of sphingosine-1-phosphate: therapeutic targets. Pharmacol Rev. 2008;60(2):181-195.

67. Xu Y, Xiao YJ, Zhu K, et al. Unfolding the pathophysiological role of bioactive lysophospholipids. Curr Drug Targets Immune Endocr Metabol Disord. 2003;3(1):23-32

68. Pini A, Mannaioni G, Pellegrini-Giampietro D, et al. The role of cannabinoids in inflammatory modulation of allergic respiratory disorders, inflammatory pain and ischemic stroke. Curr Drug Targets. 2012;13(7): 984-993.

69. Hermanson DJ, Marnett LJ. Cannabinoids, endocannabinoids, and cancer. Cancer Metastasis Rev. 2011;30(3-4):599-612.

70. Mallat A, Teixeira-Clerc F, Deveaux V, Manin S, Lotersztajn S. The endocannabinoid system as a key mediator during liver diseases: new insights and therapeutic openings. Br J Pharmacol. 2011;163(7): 1432-1440.

71. Alhouayek M, Muccioli GG. The endocannabinoid system in inflammatory bowel diseases: from pathophysiology to therapeutic opportunity Trends Mol Med. 2012;18(10):615-625.
Cancer Management and Research

\section{Publish your work in this journal}

Cancer Management and Research is an international, peer-reviewed open access journal focusing on cancer research and the optimal use of preventative and integrated treatment interventions to achieve improved outcomes, enhanced survival and quality of life for the cancer patient The journal welcomes original research, clinical \& epidemiological

\section{Dovepress}

studies, reviews \& evaluations, guidelines, expert opinion \& commentary, case reports \& extended reports. The manuscript management system is completely online and includes a very quick and fair peerreview system, which is all easy to use. Visit http://www.dovepress.com/ testimonials.php to read real quotes from published authors. 